We thank Mr J. Clifford, Mr W. K. Thompson and Dr W. 'T. Pike for their help and Dr A. D. Bangham, Dr J. Hockey and Dr C. J. Danby for useful discussions.

E. WILLis

G. K. RENNIE

C. SMart

B. A. Pethica

Unilever Research Laboratory,

Port Sunlight,

Cheshire.

Received November 27, 1968; revised January 22, 1969

${ }^{1}$ Derjaguin, B. V., Churaev, N. V., Fedyakin, N. N., Talaev, M. V., and Ershova, I. G., Izv. Akad. Nauk SSSR, (Russ.), 10, 2178 (1967); Bull. USSR Chem. Sci. (Eng.), 2095 (1967).

${ }^{2}$ Irenniker, J. C., Rev. Mod. Phys., 21, 322 (1949).

${ }^{3}$ Bangham, A. D., and Bangham, D. R., Nature, 219, 1151 (1968).

4 Anisimova, V. I., Derjaguin, B. V., Ershova, I. G., Lychnikov, D. S. Rabinovich, Ya. I., Simonova, U.' K. L., and Churaev, N. V., Russ. J. Phys. Chem., 41, 1282 (1967).

S Fedyakin, N. N., Derjaguin, B. V., Norikova, A. V., and Talaev, M. V., DAN SSSR, 165, 862 (1965).

\section{Exchangeable Acidity in Unburnt Colliery Spoil}

The more usual methods of soil extraction and chemical analysis are not entirely applicable to assessment of the potential of unburnt colliery spoil as a medium for plant growth. This is particularly true for spoil heaps in the West Riding of Yorkshire with surface spoil $p H$ values well below $4 \cdot 5$. Such spoil often contains $\mathrm{FeS}_{2}$ which oxidizes to produce $\mathrm{Fe}^{++}, \mathrm{SO}_{4}^{--}$and $\mathrm{H}^{+}$. It may also contain the carbonate mineral ankerite which is potentially capable of neutralizing the acidity. These reactions produce large quantities of soluble salts, chiefly sulphates.

Three sites in the West Riding of Yorkshire have been investigated to obtain information on the exchangeable cation status in the surface spoil. These sites were Bull. eroft (SE535098), Hound Hill (SE337046) and Maltby Main (SK545925), and the surface age of the spoil was $10 \mathrm{yr}, 50 \mathrm{yr}$ and $8 \mathrm{yr}$ respectively. Twelve random samples of surface spoil $(0-10 \mathrm{~cm})$ were taken, each yielding about $5 \mathrm{~kg}$ of spoil, and each sample was air-dried before sieving through a $1 \mathrm{~cm}$ diameter riddle. The determinations were carried out on separate $10 \mathrm{~g}$ sub. samples of the $\leq 1 \mathrm{~cm}$ fraction.

Exchangeable acidity was estimated by the $\mathrm{BaCl}_{2}-$ triethanolamine method ${ }^{1}$ and total cation exchange capa. city by $\mathrm{NH}_{4}{ }^{+}$saturation ${ }^{2}$. The method described by Jackson ${ }^{3}$, in which the spoil is treated with $0 \cdot 1 \mathrm{~N} \mathrm{HCl}$, was used as a measure of acid extractable cations. Where ankerite is present in the spoil, this procedure gives a measure of its potential neutralizing capacity. The $p \mathrm{H}$ was measured using a glass electrode in a $2: 10 \cdot 1 \mathrm{M} \mathrm{CaCl}_{2}-$ spoil suspension.

Table 1. Mean values and SIgNificant DIfFerence $(P=0.05)$ FOR CERTAIN SPOIL FACTORS FOR THREE SITES

\begin{tabular}{lrccc}
\multicolumn{1}{c}{ Site } & Total & Exch. & Acid extr. & \\
C.F.C. & acidity & cation & $p \mathbf{H}$ \\
Bullcroft & $13 \cdot 22$ & $19 \cdot 75$ & -0.33 & 2.76 \\
Hound Hill & $10 \cdot 88$ & $0 \cdot 03$ & $46 \cdot 42$ & $3 \cdot 43$ \\
Maltby Main & $10 \cdot 64$ & $6 \cdot 70$ & $99 \cdot 00$ & 3.75 \\
lsd $(P=0.05)$ & 0.94 & $2 \cdot 09$ & 35.81 & 1.25
\end{tabular}

Table 1 shows mean values for the four sets of determinations for each site, together with the significant difference between means $(P=0 \cdot 05)$.

Fig. 1 shows the regression of the ratio of the exchangeable acidity to total cation exchange capacity on acid extractable cations and shows a consistent relationship between the degree of saturation of the ion exchange sites

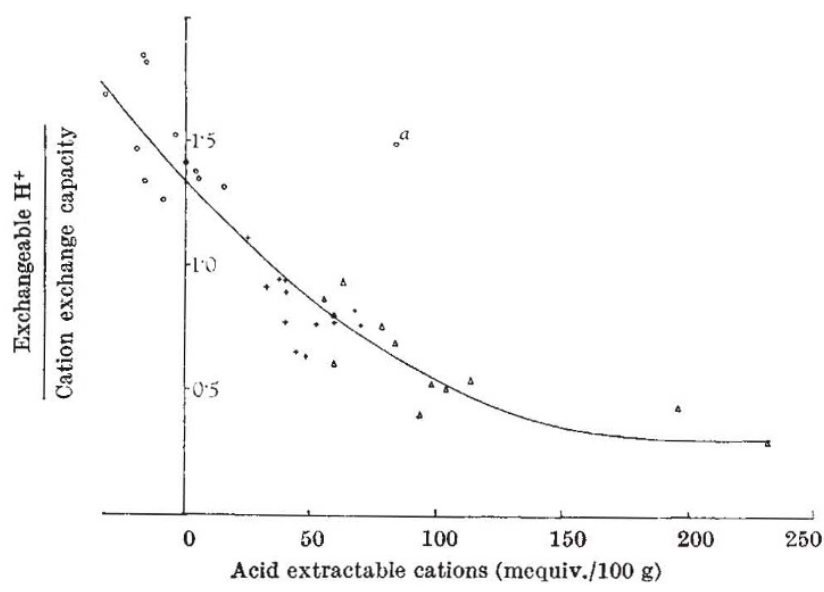

Fig. 1. The relationship between the exchangeable acidity : total cation exchange capacity ratio and acid extractable cations for unburnt spoil samples from three sites. O, Bullcroft; + , Hound Hill; $\triangle$, Maltby Main. Point $a$ has been omitted in calculating the regression: $y=1.341-$

with acidic ions, and the potential neutralizing capacity of the spoil. It also indicates that some spoil (Bullcroft) has no net neutralizing capacity. Field experience indicates that this site is particularly inhospitable to plant establishment and growth. The values recorded for the exchangeable acidity of spoil may include acidic ions not adsorbed on exchange sites, hence the values of greater than unity for the saturation ratio. It has been established (unpublished work of M. E. P.) that the detrital fraction of the spoil contains significant quantities of amorphous aluminium hydroxides which may become a source of additional acidic cations in pyritic spoil.

Confirmation of a simple relationship such as this may help to identify problem sites which are unlikely to respond to conventional amelioration treatments for reclamation.

We thank the West Riding County Council and the Nuffield Foundation for supporting this work.

M. J. Chadwick

S. M. CORNWELL*

M. E. Palmer

Department of Biology,

University of York,

Heslington, York.

Received February 25, 1969.

- Present address: Department of Landscape Architecture, University of Sheffield, Sheffield 10.

${ }^{1}$ Chapman, H. D., and Pratt, P. F., in Methods for Analysis of Soils, Plants and Waters (Calif. Univ., 1961).

' Black, C. A., Evans, D. D., White, J. L., Ensminger, L. E., and Clark, F. E., in Methods of Soil Analysis (Amer. Soc. of Agronomy, Madison, 1965). 3 Jackson, M. L., in Soil Chemical Analysis (Constable, London, 1958).

\section{Quenching of the Fluorescence of the Cerous Ion in Aqueous Solution by some Organic Ligands}

THE fluorescence of the cerous ion in aqueous solution has been the subject of a number of studies ${ }^{1-3}$. The emission maximum occurs at about $355 \mathrm{~nm}$, this being excited by absorption at about 265 and $305 \mathrm{~nm}$. The fluorescence is little affected by temperature in the range $10^{\circ}-40^{\circ} \mathrm{C}$, or by strong acids. Nitric acid, however, oxidizes the cerium to the non-fluorescent ceric state. The fluorescence is also affected by the presence of the ceric ion ${ }^{1}$ and of some other cations ${ }^{2}$. 